\title{
Is There a Correlation between the Pelvic Floor Muscle Functions and the Strength of the Hip Muscles in Female with Stress Urinary Incontinence?
}

\author{
Ui-jae Hwang, PT, Ph.D ${ }^{1}$; Jae-seop Oh, PT, Ph.D²; Moon-hwan Kim, PT, Ph.D ${ }^{3}$ \\ ${ }^{1}$ Department of Physical Therapy, Graduate School, Yonsei University, Wonju, South Korea. \\ ${ }^{2}$ Department of Physical Therapy, Inje University, Gimhae, Korea \\ ${ }^{3}$ Department of Rehabilitation Medicine, Wonju Severance Christian Hospital, Wonju, South Korea.
}

Background Because the hip muscles could affect pelvic floor muscle (PFM) function and tension of endopelvic fascia, contraction of hip muscles has been applied for stress urinary incontinence (SUI) intervention as co-contraction between hip muscles and PFM.

Purpose The purpose of current study was to confirm the relationship between hip muscles strength and PFM functions in female with SUI.

Study design Cross sectional study

Methods Thirty-three female with SUI were recruited for the present study. PFM strength and endurance were measured by perineometer (unit: $\mathrm{mmHg}$ ). Hip extensor, abductor, adductor and gluteal squeeze strength were measured by Smart KEMA tension sensor (unit: kg/body weight). The significance of the correlations between hip muscles strength and PFM functions were assessed using Pearson correlation coefficients.

Results There were not significant correlations between PFM functions (strength and endurance) and hip extensor, abductor, adductor and gluteal squeeze strength.

Conclusions These findings could indicate the difficulty of co-contraction of hip abductor, adductor, extensor and gluteal squeeze with PFM in female with SUI, which is caused by PFM dysfunction.

Key words Hip muscles; Pelvic floor muscle; Strength; Stress urinary incontinence.

\author{
JMST \\ 2020; 4(2): 51-57 \\ Published Online \\ Dec 31, 2020 \\ pISSN 2635-8573 \\ eISSN 2635-8581 \\ Article History \\ Received 28 Aug 2020 \\ Revised 11 Sep 2020 \\ (1st) \\ Revised 14 Sep 2020 \\ (2nd) \\ Accepted 18 Sep 2020

\section{CONTACT} \\ agafimu@hanmail.net \\ Moon-hwan Kim, \\ Department of \\ Rehabilitation Medicine, \\ Wonju Severance \\ Christian Hospital, \\ Wonju, South Korea. \\ This is an Open-Access article \\ distributed under the terms of \\ the Creative Commons Att- \\ ribution Non-Commercial Li- \\ cense (http $/ /$ creativecommons. \\ org/licenses/by-nc/4.0) which \\ permits unestich \\ permits unrestricted non-co- \\ mercial use, distribution, \\ and reproduction in any me- \\ dium, provided the origina \\ work is properly cited.
}

\section{INTRODUCTION}

Stress urinary incontinence (SUI) is defined involuntary loss of urine on exertion, effort, sports activities, coughing or sneezing ${ }^{1,2}$ and is widespread, ${ }^{3}$ although it seems to be undertreated. ${ }^{4}$ Pelvic floor muscle (PFM) training is suggested as first-line and non-invasive intervention for SUI. ${ }^{5}$ PFM training has discouraged compensatory muscle contractions such as abdominals, gluteals and hip adductors. ${ }^{6,7}$ Although it is difficult to contract accurately the PFM, ${ }^{6,8}$ the concern remains that compensating other muscle activity would detract from a proper contraction of the PFM. ${ }^{9}$
SUI could be related to musculoskeletal dysfunction, such as low back and pelvic pain and sacroiliac joint dysfunction. Poor control of the PFM, including the levator ani, sphincter muscles, and urogenital diaphragm can be contribute to SUI. ${ }^{9,10}$ Strengthening of PFM has been applied to improve symptom of incontinence in female. ${ }^{7,11}$ Other muscles of the pelvis and hip have been linked to PFM dysfunction. ${ }^{12} \mathrm{PFM}$ alone is difficult to maintain sufficient tension or produce enough force to encounter intra-abdominal pressure and maintain continence during jumping and sneezing, where female with SUI often areal difficulty maintaining continence. ${ }^{12}$ This indicates that other anatomi- 
cal structures, such as connective tissue, fascia and additional muscles (abdominal and hip muscles) would be important contributors to normal PFM function. ${ }^{12}$ Because, in particular, the obturator internus shares a fascial attachment with the PFM, the obturator internus could affect PFM function and tension of endopelvic fascia. ${ }^{13}$

Previous studies have confirmed the relationship between auxiliary muscle contractions and PF muscle activity. Bo and Stien have confirmed PFM activity during gluteal and hip adductor contractions. ${ }^{14}$ Sapsford et al. have demonstrated a relationship between PFM activity and transversus abdominis contractions. ${ }^{15,16}$ Underwood et al. have reported significant weakness in the hip abductors of female with SUI when compared with healthy controls. ${ }^{17}$ However, no studies have investigated the correlation between hip muscles and PFM strength.

Thus, the purpose of present study was to investigate the relationship between hip extensor, abductor, adductor and gluteal squeeze strength and PFM strength and endurance in female with SUI. We hypothesize that the hip abductor and extensor strength may be associated with PFM strength and endurance, because of the inexistence anatomical and mechanical association between hip adductors and PFM. It can represent a better choice among hip extensor, abductor, adductor and gluteal squeeze, in clinical practice and protocol for PFM rehabilitation, ${ }^{18}$ when looking for strategies to improve proprioception and PFM recruitment, as well as facilitating rehabilitation.

\section{METHODS}

\section{Subjects}

The participants were recruited by advertisements that provided the telephone contact to the interested parties. After contact, there were scheduled visits to confirm the inclusion and exclusion criteria in the present study.

Inclusion criteria were 1) SUI diagnosed by a urogynecologist, 2) a leakage episode occurring more than once a week, 3) generally healthy (apart from SUI), 4) body mass index $<30 \mathrm{~kg} / \mathrm{m}^{2}, 5$ ) age between 30 and 60 years, 6) nonsmoker and 7) not addicted to alcohol or drugs. Exclusion criteria were 1) pregnancy/ planning to get pregnant, 2) pelvic or abdominal surgery within the last six months and 3) PFM and hip muscle training within the last three months 4) concomitant treatment for SUI during the trial period, 5) neurological or psychiatric disease and 6) urinary tract infection.

A priori using $\mathrm{G}^{*}$ power (version 3.1.3; University of Trier, Trier, Germany) was used to calculate sample size for a power of 0.80 , an $\alpha$ level of 0.05 and a correlation of 0.5 .
If there is a significant correlation between hip muscles strength and PFM functions, it is the expected value that a correlation of at least 0.5 (moderate effect) would occur. The sample size was required at least 29 subjects.

A total of 33 participants met the inclusion and exclusion criteria (Table 1). Before the study, all subjects were explained about the all procedures of the study and signed an informed consent form approved by the Institutional Review Board of Yonsei University, Wonju (1041849-201802-BM005-01)

\section{Procedures}

From August 2018 to September 2018, PFM strength and endurance were measured at urogynecology clinic in Seoul, Korea and hip muscles strength were measured at laboratory setting. PFM strength was measured first and then, PFM endurance by urogynecologist. Hip extensor, abductor, adductor and gluteal squeeze strength were measured in random order by orthopedic physical therapist. The order of measurement of hip muscles strength was randomized by www.randomization.com.

\section{Measurement of pelvic floor muscle functions}

The PFM functions were assessed in hook-lying position by a VVP-3000 perineometer (QLMED Ltd, Gyeonggi-do, Korea) for all participants. ${ }^{19}$ The vaginal probe in perineometer is $24 \mathrm{~mm}$ in diameter and $115 \mathrm{~mm}$ in length with inserted vaginal active length of $66 \mathrm{~mm}$ and is connected to a microprocessor with latex tubing for transmission of pressure readings when the insert is compressed by vaginal wall (Figure 1). The baseline pressure as $\mathrm{mmHg}$ was recorded without voluntary PFM contraction and then was zeroed. We asked for contracting subject's PFM and to squeeze with maximum voluntary contraction (MVC) perceived effort for three seconds. Participants were instructed to pull their PFM in and up as much as possible without using of abdominal and hip muscles contraction. ${ }^{20}$ PFM strength was measured from the resting pressure line until the peak, not

Table 1. Characteristics of the participants

\begin{tabular}{cc}
\hline & $\begin{array}{c}\text { Women with stress urinary } \\
\text { incontinence }(\mathrm{n}=33)\end{array}$ \\
\hline Age $(\mathrm{yr})$ & $41.6 \pm 8$ \\
BMI $\left(\mathrm{kg} / \mathrm{m}^{2}\right)$ & $22.7 \pm 3.1$ \\
Duration of symptoms $(\mathrm{yr})$ & $12.7 \pm 11.3$ \\
Number of deliveries & $1.7 \pm 0.9$ \\
Vaginal deliveries & $1.5 \pm 1.9$ \\
\hline
\end{tabular}




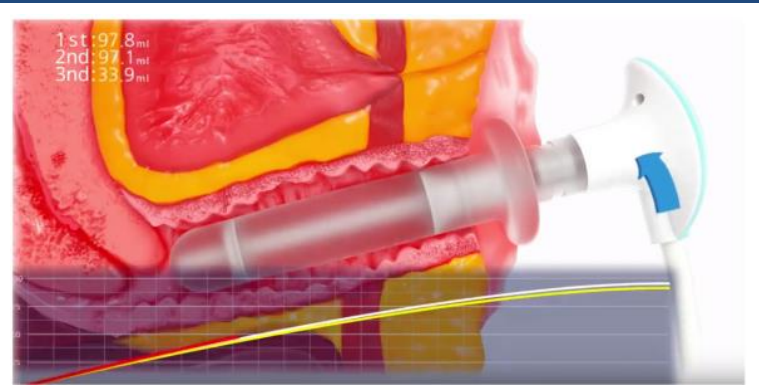

Figure 1. Perinometer for measuring pelvic floor muscle functions using vaginal probe

involving the resting pressure, reported as the mean of two MVC, and recorded as mmHg (Figure 2). ${ }^{21}$ PFM endurance was measured for the mean of contraction pressure for $10 \mathrm{~s}$, during one attempt and recorded as $\mathrm{mmHg}$ (Figure 2).

\section{Measurement of hip muscles strength}

Smart KEMA tension sensor (KOREATECH Co., Ltd., Seoul, Korea) was used to measure isometric strength and to control initial tension on belt by $3 \mathrm{kgf}$. Tension sensor was measurable up to $1960 \mathrm{~N}$, with an accuracy of $4.9 \mathrm{~N}$ and a $10 \mathrm{~Hz}$ sampling frequency. The force signals were measured from maximal voluntary isometric contraction of the hip extensor, abductor, adductor and gluteal squeeze strength. Data measured by sensors were transferred to a tablet via Bluetooth device connection and analyzed with the Smart KEMA application (KOREATECH Co., Ltd., Seoul, Korea). Hip muscles strength testing by measured Smart KEMA tension sensor showed excellent intra(ICC3,1>0.95) and inter-rater (ICC2,1>0.95) test reliability. $^{22}$
For measurement of hip muscles strength, the belt length was adjusted for measure isometric strength in start position. Participants were asked hold maximal strength for 5 seconds and middle 3 seconds was calculated for average. The hip extensor, abductor and adductor strength were calculated the average value of both side. Table 2 shows the position and procedure for each muscle strength test.

\section{STATISTICAL ANALYSIS}

All statistical analyses were performed using SPSS software (ver. 18.0; SPSS Inc., Chicago, IL, USA) with alpha set at 0.05 . The Kolmogorov-Smirnov Z-test was applied to confirm the normality of the data distribution. Pearson's correlation coefficients were constructed to examine the relationships between hip extensor, abductor, adductor and gluteal squeeze strength and PFM strength and endurance. For the $r$ value, an $r \geq 0$ and $<0.1$ was classified as no effect, $r \geq 0.1$ and $<0.3$ was a small effect, $r \geq 0.3$ and $<0.5$ was a moderate effect, and $r \geq 0.5$ was a large effect.

\section{RESULTS}

Table 3 shows the correlation coefficients between PFM functions and hip muscles strength. There were not significant correlations between PFM strength and hip extensor strength ( $r=0.078)$, hip abductor strength $(r=0.091)$, hip adductor strength $(\mathrm{r}=0.119)$ and gluteal squeeze strength $(\mathrm{r}=-0.036)$ (Table 3). Also, there were not significant correlations between PFM endurance and hip extensor strength ( $\mathrm{r}=0.067)$, hip abductor strength $(\mathrm{r}=-0.016)$, hip adductor strength $(\mathrm{r}=0.112)$ and gluteal squeeze strength $(\mathrm{r}=0.112)$ (Table 3).

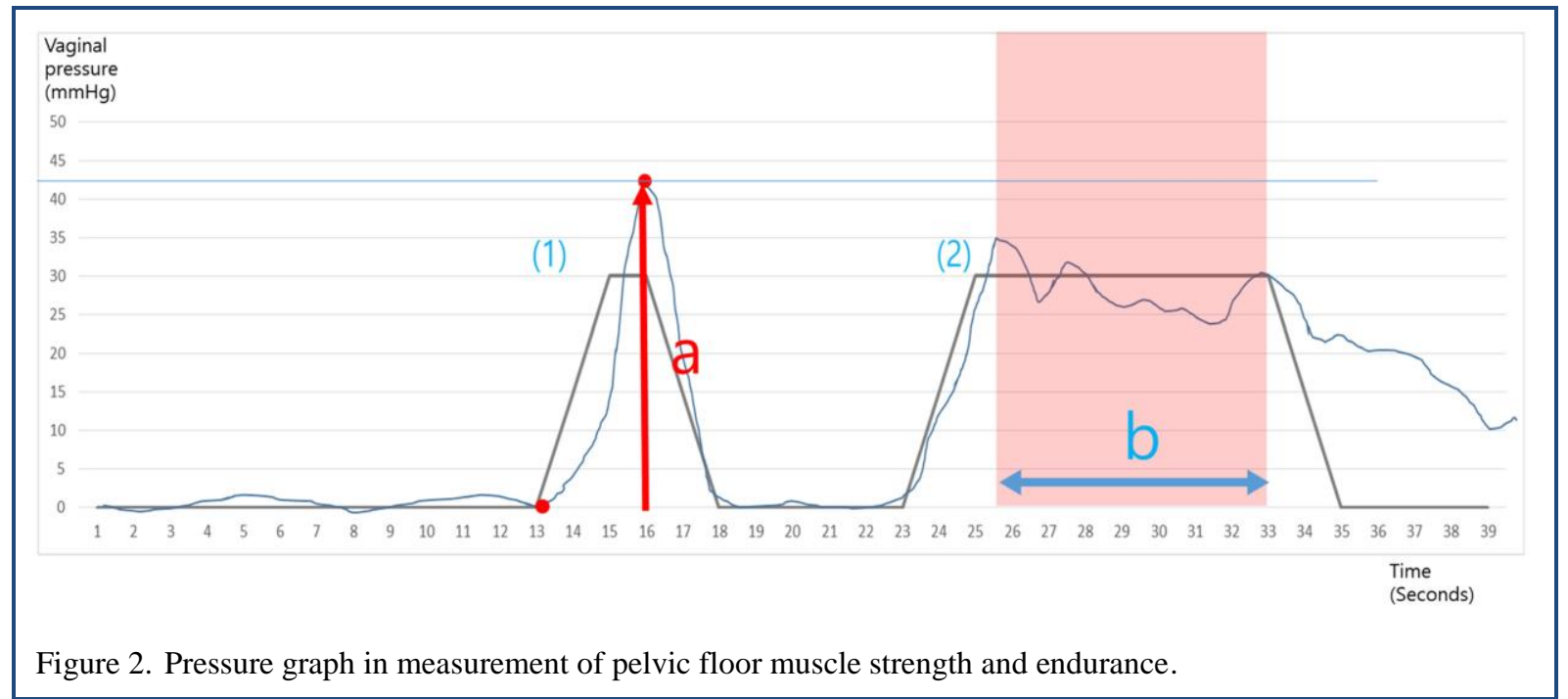


Table 2. Description of the hip muscles strength measurements

\begin{tabular}{|c|c|c|c|c|}
\hline $\begin{array}{c}\text { Strength } \\
\text { measurements }\end{array}$ & Strap placement & Position & Procedure & Figure \\
\hline Hip extensor & Distal thigh & Prone & $\begin{array}{l}\text { The examiner controlled the } \\
\text { subject's lumbopelvic rotation } \\
\text { during hip extension (HE). } \\
\text { Subjects performed HE against a } \\
\text { strap to maximal voluntary } \\
\text { isometric contraction (MVIC) } \\
\text { twice. }\end{array}$ & \\
\hline Hip abductor & Ankle & Supine & $\begin{array}{l}\text { The examiner controlled the } \\
\text { subject's lumbopelvic side- } \\
\text { bending during hip abduction. The } \\
\text { hip and knee joint of the dominant } \\
\text { leg was extended to } 0^{\circ} \text {. Subjects } \\
\text { performed hip abduction against a } \\
\text { strap to MVIC twice. }\end{array}$ & \\
\hline Hip adductor & Ankle & Supine & $\begin{array}{l}\text { The examiner controlled the } \\
\text { subject's lumbopelvic side- } \\
\text { bending during hip adduction. The } \\
\text { hip and knee joint of the dominant } \\
\text { leg was extended to } 0^{\circ} \text {. Subjects } \\
\text { performed hip adduction against a } \\
\text { strap to MVIC twice. }\end{array}$ & \\
\hline Gluteal squeeze & $\begin{array}{c}\text { Gluteus covers at } \\
\text { greater trochanter } \\
\text { level }\end{array}$ & Standing & $\begin{array}{l}\text { Strap covered gluteus at greater } \\
\text { trochanter level. When the subject } \\
\text { actively contracts the gluteal } \\
\text { muscle, the repulsive force occurs } \\
\text { in tension sensor by muscle valley } \\
\text { enlargement by the gluteal } \\
\text { squeezing. Subjects performed } \\
\text { gluteal squeezing against a strap } \\
\text { to MVIC twice. }\end{array}$ & \\
\hline
\end{tabular}

Table 3. The correlation coefficients between PFM functions and hip muscles strength

\begin{tabular}{|c|c|c|c|c|}
\hline & \multicolumn{2}{|c|}{ Pelvic floor muscle strength } & \multicolumn{2}{|c|}{ Pelvic floor muscle endurance } \\
\hline & $\mathrm{r}$ & $\mathrm{p}$ & $\mathrm{r}$ & $\mathrm{p}$ \\
\hline Hip extensor strength & 0.078 & 0.668 & 0.067 & 0.712 \\
\hline Hip abductor strength & 0.091 & 0.616 & -0.016 & 0.929 \\
\hline Hip adductor strength & 0.119 & 0.510 & 0.112 & 0.533 \\
\hline Gluteal squeeze strength & -0.036 & 0.843 & 0.112 & 0.533 \\
\hline
\end{tabular}

\section{DISCUSSION}

The effect of PFM training for SUI have been supported by studies suggesting that PFM training produces greater outcomes than no treatment, inactive control treatment, or placebo drug. ${ }^{11}$ Our main results do not support our hypo- thesis, which presents that there were not significant correlations between PFM functions and strength of hip extensor, abductor, adductor, and gluteal squeeze in female with SUI. This hypothesis was based on anatomical supposition that the obturator internus could play role of myofascial force transmission, which is deep hip external rotator 
muscles and to be connected with the levator ani. Rotator cuff, such as the gluteus maximus and gluteus medius tendons, associated with the hip joint and pelvis. ${ }^{13}$ However not only hip adductor strength but also hip extensor, abductor and gluteal squeeze strength were not related to PFM functions.

Strengthening the hip muscles has been recommended as one component of intervention for improving SUI. ${ }^{23}$ Also, previous studies have suggested that hip abductor, adductor, extensor and external rotator muscles co-contract with PFM contraction. ${ }^{14,24}$ However, other study only hip abduction strength among strength of hip flexor, extensor abductor, adductor, external rotator and internal rotator differed between female with and without SUI. ${ }^{17}$ Also, the absolute difference in hip abduction isometric strength between groups was only $2.6 \%$ body weight. ${ }^{17}$ In addtion, the cocontraction of the PFM and the hip adductors or abductors did not increase PFM efficiency about increasing or holding PFM strength. ${ }^{25}$ Similarly, during a PFM contraction, cocontractions of other muscle (diaphragm, abdominal muscles, hip extensor, hip abductor, adductor, external rotator, and internal rotator) groups did not exceed the intravaginal pressure rise. ${ }^{21}$

Given the absence or a statistically significant relationship between PFM functions and hip extensor, abductor, adductor and gluteal squeeze strength in this study, one might logically question the rationale for including hip extensor, abductor, adductor and gluteal squeeze strengthening as part of a SUI rehabilitation and intervention strategy. In the present study, the hip external rotator strength was not measured. If obturator internus function is critical to PFM function, the hip external rotator strength may have been selectively correlated with the PFM functions. However, obturator internus only contributes a small proportion to the force generation of the hip external rotators collectively, similarly other muscles (hip extensor, abductor and adductor strength), then hip external rotation strength may be expected to have a poor relationship with PFM functions. Also, the reason for this study result could be the difficulty of cocontraction of hip abductor, adductor, extensor and external rotator muscles with PFM in female with SUI, which is caused by PFM dysfunction. Previous studies have determined the co-contraction of hip abductor, adductor, extensor and external rotator muscles with PFM only in healthy female. ${ }^{14,24}$ If the ability of PFM contraction is insufficient and dysfunction, it may be difficult to cause co-contraction of the hip muscles and PFM. Therefore, strengthening the hip muscles to stimulate co-contraction of the PFM as a rehabilitation strategy for improving PFM functions, as SUI intervention, may not be an appropriate strategy

The present study had some limitations. First, the sample size is small. Thus, further study is needed to generalize the experimental results. Second, we did not measure electromyography of hip muscles and PFM for exactly detecting co-contraction. Further study needs to determine activity of hip muscles and PFM during PFM or hip muscles contraction in female with SUI. Third, we did not determine a correlation between hip muscles strength and SUI symptoms or urinary leakage. Thus, further study needs to confirm relationship between hip muscles strength and SUI symptoms or urinary leakage to find the possibility of SUI intervention.

\section{CONCLUSIONS}

There were no significant correlations between PFM functions and strength of hip extensor, abductor, adductor, and gluteal squeeze in female with SUI. These findings could indicate the difficulty of co-contraction of hip abductor, adductor, extensor and gluteal squeeze with PFM in female with SUI, which is caused by PFM dysfunction. Therefore, strengthening the hip muscles to co-contract PFM may be difficult to recommend for improving PFM functions in female with SUI.

\section{Key Points}

Question Is there an association between the PFM functions and the strength of the hip muscles in female with SUI?

Findings There were not significant correlations between PFM strength and hip extensor, abductor, adductor and gluteal squeeze strength.

There were not significant correlations between PFM endurance and hip extensor, abductor, adductor and gluteal squeeze strength.

Meaning These findings could indicate the difficulty of cocontraction of hip abductor, adductor, extensor and gluteal squeeze with PFM in female with SUI.

Strengthening the hip muscles to co-contract PFM may be difficult to recommend for improving PFM functions in female with SUI.

\section{Article information}

Conflict of Interest Disclosures: None.

Funding/Support: None.

Acknowledgment: None.

Ethic Approval: Institutional Review Board of Yonsei University, Wonju (1041849-201802-BM-005-01). 


\section{REFERENCES}

1. Buckley BS, Lapitan MCM. Prevalence of urinary incontinence in men, women, and children-current evidence: findings of the Fourth International Consultation on Incontinence. Urology. 2010;76(2):265-270.

2. Abrams P, Cardozo L, Fall M, et al. The standardisation of terminology of lower urinary tract function: report from the Standardisation Sub-committee of the International Continence Society. Neurourology and Urodynamics. 2002;21(2):167-178.

3. Thom DH, Rortveit G. Prevalence of postpartum urinary incontinence: a systematic review. Acta Obstetricia et Gynecologica Scandinavica. 2010;89(12):1511-1522.

4. Fine P, Burgio K, Borello-France D, et al. Teaching and practicing of pelvic floor muscle exercises in primiparous women during pregnancy and the postpartum period. American Journal of Obstetrics and Gynecology. 2007; 197(1):107. e101-107. e105.

5. Syan R, Brucker BM. Guideline of guidelines: urinary incontinence. BJU International. 2016;117(1):20-33.

6. Talasz H, Himmer-Perschak G, Marth E, Fischer-Colbrie J, Hoefner E, Lechleitner M. Evaluation of pelvic floor muscle function in a random group of adult women in Austria. International Urogynecology Journal. 2008; 19(1):131-135.

7. Bø K. Pelvic floor muscle strength and response to pelvic floor muscle training for stress urinary incontinence. Neurourology and Urodynamics: Official Journal of the International Continence Society. 2003;22(7):654-658.

8. Moen MD, Noone MB, Vassallo BJ, Elser DM. Pelvic floor muscle function in women presenting with pelvic floor disorders. International Urogynecology Journal. 2009;20(7):843-846.

9. Bø K, Mørkved S, Frawley H, Sherburn M. Evidence for benefit of transversus abdominis training alone or in combination with pelvic floor muscle training to treat female urinary incontinence: a systematic review. Neurourology and Urodynamics: Official Journal of the International Continence Society. 2009;28(5):368-373.

10. A. Ashton-Miller DH, John OL Delancey, James. The functional anatomy of the female pelvic floor and stress continence control system. Scandinavian Journal of Urology and Nephrology. 2001;35(207):1-7.

11. Dumoulin C, Cacciari LP, Hay-Smith EJC. Pelvic floor muscle training versus no treatment, or inactive control treatments, for urinary incontinence in women. Cochrane Database of Systematic Reviews. 2018(10).

12. Tuttle LJ, Nguyen OT, Cook MS, et al. Architectural design of the pelvic floor is consistent with muscle functional subspecialization. International Urogynecology Journal. 2014;25(2):205-212.

13. Tuttle LJ, DeLozier ER, Harter KA, Johnson SA, Plotts CN, Swartz JL. The role of the obturator internus muscle in pelvic floor function. Journal of Women's Health Physical Therapy. 2016;40(1):15-19.

14. Bø K, Stien R. Needle EMG registration of striated urethral wall and pelvic floor muscle activity patterns during cough, Valsalva, abdominal, hip adductor, and gluteal muscle contractions in nulliparous healthy females. Neurourology and Urodynamics. 1994;13(1): 35-41.

15. Sapsford R, Hodges P, Richardson C, Cooper D, Markwell S, Jull G. Co-activation of the abdominal and pelvic floor muscles during voluntary exercises. Neurourology and Urodynamics: Official Journal of the International Continence Society. 2001;20(1):31-42.

16. Sapsford RR, Hodges PW. Contraction of the pelvic floor muscles during abdominal maneuvers. Archives of Physical Medicine and Rehabilitation. 2001;82(8):10811088.

17. Underwood DB, Calteaux TH, Cranston AR, Novotny SA, Hollman JH. Hip and pelvic floor muscle strength in women with and without stress urinary incontinence: a case-control study. Journal of Women's Health Physical Therapy. 2012;36(1):55-61.

18. Hofbauer J, Preisinger F, Nürnberger N. The value of physical therapy in genuine female stress incontinence. Zeitschrift Fur Urologie Und Nephrologie. 1990;83(5): 249.

19. Mohseni-Bandpei MA, Rahmani N, Behtash H, Karimloo M. The effect of pelvic floor muscle exercise on women with chronic non-specific low back pain. Journal of Bodywork and Movement Therapies. 2011;15(1):75-81.

20. Bø K, Kvarstein B, Hagen R, Larsen S. Pelvic floor muscle exercise for the treatment of female stress urinary incontinence: I. Reliability of vaginal pressure measurements of pelvic floor muscle strength. Neurourology and Urodynamics. 1990;9(5):471-477.

21. Tennfjord MK, Engh ME, Bø K. An intra-and interrater reliability and agreement study of vaginal resting pressure, pelvic floor muscle strength, and muscular endurance using a manometer. International Urogynecology Journal. 2017;28(10):1507-1514.

22. Ahn S-H, Hwang U-J, Jung S-H, Kim H-A, Kim J-H, Kwon O-Y. Hip external rotator strength and compensatory movement in three different positions. Health. 2018;10(01):132.

23. Hulme JA. Research in geriatric urinary incontinence: pelvic muscle force field. Topics in Geriatric Reha- 
bilitation. 2000;16(1):10-21.

24. Peschers U, Gingelmaier A, Jundt K, Leib B, Dimpfl T. Evaluation of pelvic floor muscle strength using four different techniques. International Urogynecology Journal. 2001;12(1):27-30.
25. Amorim AC, Cacciari LP, Passaro AC, et al. Effect of combined actions of hip adduction/abduction on the force generation and maintenance of pelvic floor muscles in healthy women. Plos one. 2017;12(5): e0177575. 